\title{
MR imaging of Duane retraction syndrome
}

\author{
Menachem M. Gold • Jacques Romano
}

Received: 2 October 2008 /Accepted: 14 October 2008 / Published online: 11 November 2008

(C) Springer-Verlag 2008

An 11-year-old girl presented with a history of inability to abduct the left eye since birth (Fig. 1, below). Highresolution MR imaging through the brainstem showed the right abducens nerve entering Dorello's canal (Fig. 2, arrow) and absence of the left abducens, confirming the diagnosis of Duane retraction syndrome (DRS).

DRS, as originally described in 1905 , is a congenital eye movement disorder consisting of an abduction deficit accompanied by retraction of the globe on attempted adduction [1]. DRS accounts for approximately $1 \%$ of strabismus cases in the general population and involves the left eye in about $75 \%$ of patients [2]. Although many pathophysiologic processes have been posited as mediating DRS, the most widely accepted is absence or hypoplasia of the abducens nucleus with anomalous innervation of the lateral rectus muscle by branches of the oculomotor nerve [2]. Absence of the abducens nerve on MR imaging can help distinguish DRS from clinical mimickers such as chronic abducens palsy and may assist in presurgical planning for strabismus correction.

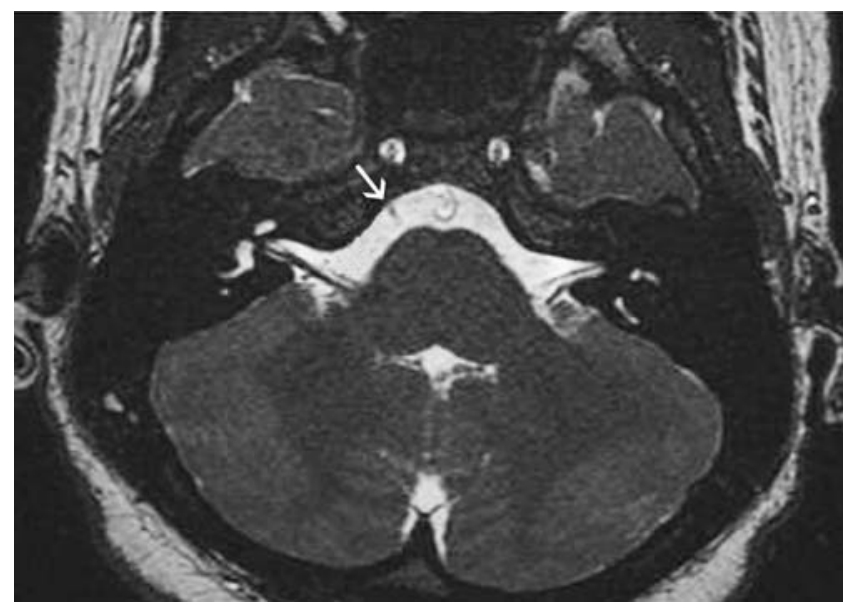

Fig. 2 Axial MR image

Fig. 1 Photograph demonstrating abduction deficit on the left

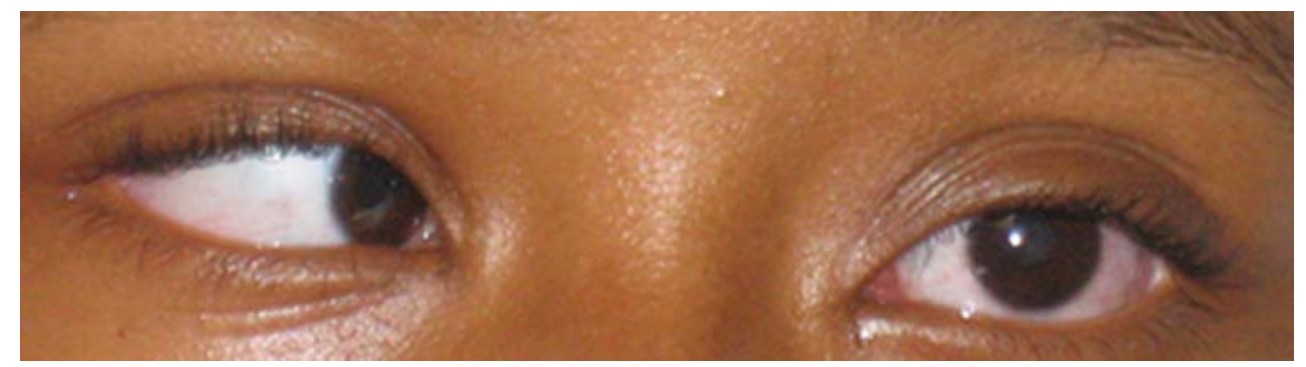

\section{References}

M. M. Gold $(\bowtie) \cdot$ J. Romano

Department of Radiology, Montefiore Medical Center,

Albert Einstein College of Medicine,

111 E. 210th St.,

Bronx, NY 10467, USA

e-mail: megold@montefiore.org
1. Duane A (1905) Congenital deficiency of abduction associated with impairment of adduction, retraction movements, contraction of the palpebral fissure and oblique movements of the eye. Arch Ophthalmol 114:1255-1256

2. DeRespinis PA, Caputo AR, Wagner RS et al (1993) Duane's retraction syndrome. Surv Ophthalmol 38:257-288 